\title{
Buckling curves for stainless steel tubular columns
}

\author{
Sheida Afshan*,a ${ }^{\text {, Ou Zhao }}{ }^{\mathrm{b}}$, Leroy Gardner ${ }^{\mathrm{c}}$ \\ ${ }^{a}$ Brunel University London, Dept. Mechanical, Aerospace and Civil Engineering, UK \\ sheida.afshan@brunel.ac.uk, \\ ${ }^{\mathrm{b}}$ Nanyang Technological University, School of Civil and Environmental Engineering, Singapore \\ ou.zhao@ntu.edu.sg \\ 'Imperial College London, Dept. Civil and Environmental Engineering, UK \\ leroy.gardner@imperial.ac.uk
}

\begin{abstract}
Towards the development of more resilient and sustainable structures, interest in the use of high performance construction materials, such as stainless steels, has increased in recent years. Recent studies [1] have highlighted a number of deficiencies in the flexural buckling provisions given in Eurocode 3: Part 1.4 for the design of stainless steel compression members. Therefore, this study aims to investigate the effect of production route (cold-formed and hot-finished) and material grade (austenitic, duplex and ferritic) on the behaviour and design of stainless steel square and rectangular hollow section columns. Test data from the literature combined with numerical modelling data generated as part of this study are used to derive a series of buckling curves for the design of stainless steel columns. Reliability analysis in accordance with Annex D of EN 1990 has been carried out to show that the proposed buckling curves comply with the Eurocode reliability requirements.
\end{abstract}

Keywords: Buckling curves, Columns, Stainless steel

\section{INTRODUCTION}

Stainless steel has many desirable characteristics which can be exploited in a wide range of construction applications. It is corrosion-resistant and long-lasting, making thinner and more durable structures possible. In recognition of the many desirable properties of stainless steel, a series of research projects to generate structural design rules have been carried out over past few decades leading to the development of international design standards such as EN 1993-1-4 [2]. The stress-strain behaviour of stainless steel is different from that of carbon steels in that instead of the typical linear elastic behaviour up to the yield stress and a plateau before strain hardening, it exhibits a more rounded response, with no well-defined yield stress. In addition, the stress-strain characteristics vary between the different stainless steel grades. Fig. 1 shows typical measured stress-stain curves for austenitic, duplex and ferritic stainless steel grades [3]. The non-linear stressstrain behaviour of stainless steel affects the buckling strength of columns, and members in general, and needs to be accounted for in the development of design buckling curves. This is currently not the case in EN 1993-1-4 [2], where for a given section type, one buckling curve is used for all stainless steel grades, which was shown in [2] to lead into inaccurate predictions of the member compressive resistance. This paper reports a numerical modelling study to generate structural performance data to derive buckling curves for the design of stainless steel square and rectangular hollow sections, SHS and RHS respectively, from two production processes, cold-formed and hotfinished, and three material grades, austenitic, duplex and ferritic. 


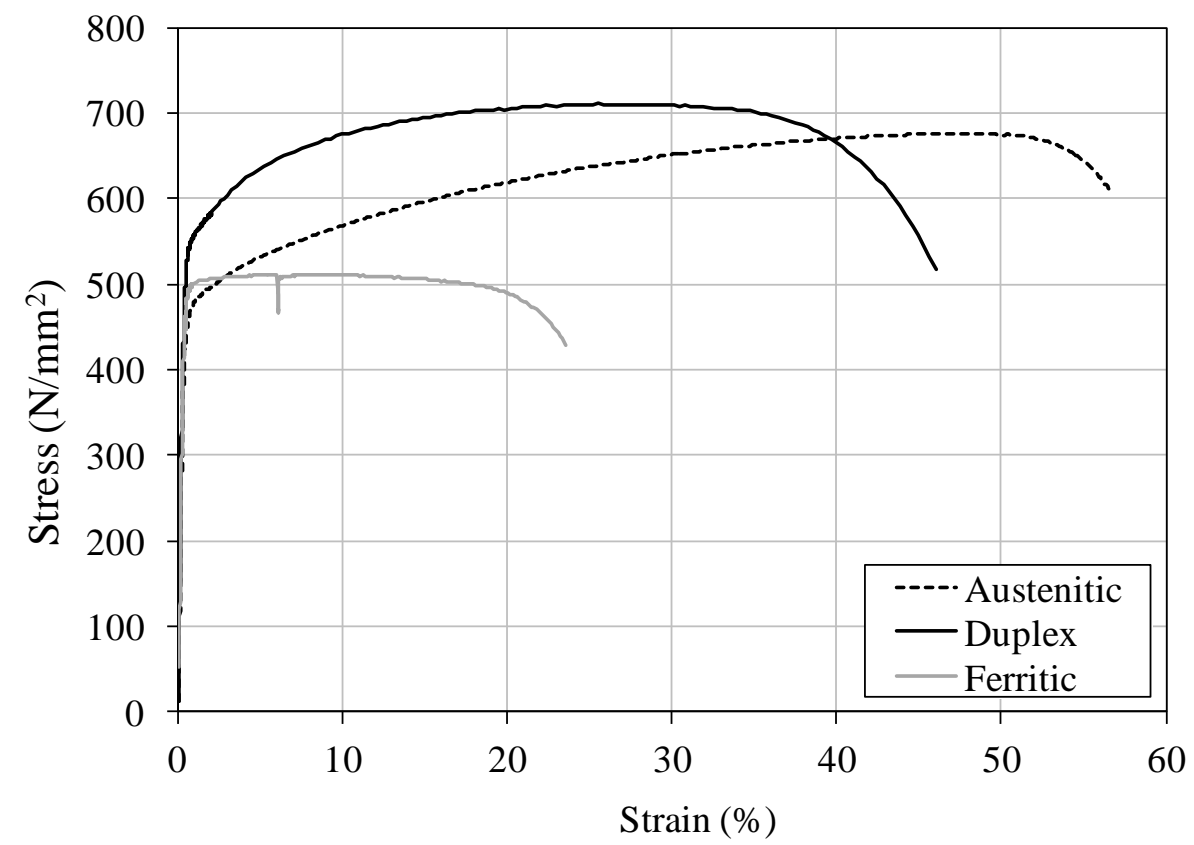

Fig. 1: Typical stress-strain curves for austenitic, duplex and ferritic stainless steel grades

\section{NUMERICAL MODELLING}

\subsection{Overview}

The nonlinear finite element analysis package ABAQUS [4] was used for conducting the numerical modelling programme. Numerical simulations were carried out on stainless steel SHS and RHS columns of varying member slenderness subjected to concentric compression. A detailed description of the development of the FE models and their validation against experimental results were presented by the authors in previous numerical studies [5] of stainless steel tubular sections under pure compression and therefore only the key features of the modelling procedures are reported herein.

\subsection{General modelling assumptions}

Shell elements were adopted to simulate the stainless steel tubular hollow section columns, as is customary for modelling of thin-walled structures. The four-noded doubly curved shell element with reduced integration and finite membrane strain S4R, which has performed well in numerous similar applications, was used. An element size equal to the cross-section thickness was used to discretise the flat portions of the modelled cross-sections, while the corner regions were assigned a finer mesh of four elements to accurately represent the curved geometry. The end section boundary conditions of the numerical models were arranged to replicate pin-ended conditions about the specified axis of buckling. Symmetry was exploited by modelling only half the cross-section and member length of the concentrically-loaded compressive members by employing suitable symmetry boundary conditions to each axis of symmetry.

\subsection{Material modelling}

The adopted material properties for the present numerical modelling were taken from a collection of previous material tests on stainless steel cold-formed SHS and RHS structural members and plate and sheet materials reported in [6]. Table 1 provides the average material properties used, where $\mathrm{f}_{0.2}$ is the $0.2 \%$ proof stress, $\mathrm{f}_{\mathrm{u}}$ is the ultimate tensile stress, $\varepsilon_{\mathrm{u}}$ is the strain at ultimate tensile stress and $\mathrm{n}$ and $\mathrm{n}_{0.2, \mathrm{u}}$ are the Ramberg-Osgood material model parameters. The Young's modulus was taken as $200000 \mathrm{~N} / \mathrm{mm}^{2}$ for all stainless steel grades. Stress-strain curves were then constructed using the two-stage Ramberg-Osgood material model proposed in [7] based on the material parameters in Table 1. The collected average flat and corner material data were used for modelling the material response of the flat faces and corner regions of the cold-formed sections, while those of the plate 
and sheet material were used for simulating the response of the hot-finished members. ABAQUS [4] requires the material properties to be specified in the form of true stress and log plastic strain for the adopted element type; these were derived from the engineering stress-strain curves. For the cold-formed sections, the curved corner region plus an extension of $2 \mathrm{t}$ were assigned the corner material properties in accordance with findings in [8], which showed that both of the aforementioned regions undergo approximately the same degree of strength enhancement during the cold-rolling process, and therefore exhibit similar stress-strain responses. Owing to the negligible influence of the membrane residual stresses on cold-formed stainless steel tubular profiles, and the inherent presence of through-thickness residual stresses in the measured material properties [5], residual stresses were not explicitly modelled in the FE models of cold-formed sections. Also, since the magnitude of measured residual stresses in hot-finished tubular sections are very low [9], as reflected by the use of buckling curve a in EN 1993-1-1 [10], residual stresses were not included in the FE models of the hot-finished sections.

Table 1: Average material properties used in numerical models

\begin{tabular}{llccccc}
\hline Grade & Type & $\mathrm{f}_{0.2}\left(\mathrm{~N} / \mathrm{mm}^{2}\right)$ & $\mathrm{f}_{\mathrm{u}}\left(\mathrm{N} / \mathrm{mm}^{2}\right)$ & $\varepsilon_{\mathrm{u}}$ & $\mathrm{n}$ & $\mathrm{n}_{0.2, \mathrm{u}}^{\prime}$ \\
\hline \multirow{3}{*}{ Austenitic } & Plate and Sheet & 296 & 628 & 0.490 & 9.1 & 2.3 \\
& Flat & 461 & 694 & 0.184 & 7.1 & 2.9 \\
& Corner & 638 & 828 & 0.205 & 6.4 & 7.1 \\
\hline \multirow{3}{*}{ Duplex } & Plate and Sheet & 556 & 771 & 0.281 & 9.3 & 3.6 \\
& Flat & 629 & 780 & 0.130 & 7.5 & 4.8 \\
& Corner & 804 & 973 & 0.032 & 6.1 & 6.7 \\
\hline \multirow{3}{*}{ Ferritic } & Plate and Sheet & 358 & 491 & 0.156 & 17.2 & 2.8 \\
& Flat & 428 & 492 & 0.062 & 11.5 & 4.6 \\
& Corner & 557 & 608 & 0.009 & 5.7 & 6.8 \\
\hline
\end{tabular}

\subsection{Geometric imperfections and boundary conditions}

All the modelled columns had pin-ended boundary condition, where the loaded end section was coupled to a concentric reference point allowing longitudinal translation and rotation about the axis of buckling; the axial load was applied to the model through this reference point. Initial geometric imperfections are introduced into structural sections during production, fabrication and handling and can significantly influence structural behaviour. Imperfection shapes of the form of the lowest global and local buckling modes obtained from a linear elastic eigenvalue buckling analysis were utilised in the present modelling. The global imperfection amplitude was set to L/1000, where $\mathrm{L}$ is the overall column length. For the local imperfection amplitude $\omega_{0}$, values predicted by the Dawson and Walker model, as adapted for stainless steel [11] given by Eq. (1), where $\mathrm{t}$ is the thickness, $\mathrm{f}_{0.2}$ is the material $0.2 \%$ proof stress and $\mathrm{f}_{\mathrm{cr}}$ is the minimum elastic buckling stress of all the plate elements making up the cross-section, were used.

$\omega_{0}=0.023\left(\frac{f_{0.2}}{f_{c r, \text { min }}}\right) t$

\subsection{Parametric studies}

For both the cold-formed and hot-finished members parametric studies were conducted where the varied parameters were: the stainless steel grade (austenitic, duplex and ferritic), the cross-section aspect ratio, the cross-section slenderness, the axis of buckling and the member slenderness. The geometric dimensions of the modelled cross-sections were fixed to $100 \times 100,150 \times 100$ and $200 \times 100$ $\mathrm{mm}$, leading to cross-section aspect ratios of 1, 1.5 and 2. For each section, two thicknesses were considered corresponding to a Class 1 and a Class 3 cross-section according to the EN 1993-1-4 [2] classification limits. For the $150 \times 100$ and $200 \times 100$ cross-sections buckling about both the major and minor axes was considered to investigate if different buckling curves should be provided for each buckling axis. For each section, the member lengths were varied, leading to a spectrum of 
member slenderness values $\bar{\lambda}=0.1-2.5$. The internal corner radii were set equal to the crosssection thickness.

\section{ANALYSIS OF RESULTS AND DESIGN GUIDANCE}

\subsection{Current design guidance for stainless steel columns}

The EN 1993-1-4 [2] design approach for flexural buckling of compression members is based on the Perry-Robertson buckling formulation with a linear imperfection parameter $\eta=\alpha\left(\bar{\lambda}-\bar{\lambda}_{0}\right)$, where $\alpha$ and $\bar{\lambda}_{0}$ are constants accounting for the effect of geometric imperfections and residual stresses on the column strength. A single buckling curve is currently provided for cold-formed open and tubular members of austenitic, duplex, and ferritic stainless steel grades. This curve was derived by calibration against the then available stainless steel test data to provide a suitably conservative fit for design purposes. For simplicity, to avoid the need for iteration and for consistency with the carbon steel approach, no explicit allowance is made for the effect of gradual material yielding in the member buckling formulations. The SEI/ASCE-8 [12] provisions for stainless steel column design allow for the non-linear stress-strain response through the use of the tangent modulus $E_{t}$ at the buckling stress though this results in an iterative design approach. In addition to the iterative method from the SEI/ASCE-8 [12] specification, an alternative explicit design procedure is also provided in the AS/NZS 4673 [13] standard for cold-formed stainless steel structures. The method is essentially the same as the EN 1993-1-4 [2] formulation for flexural buckling of compression members, except that a nonlinear expression is used for the imperfection parameter instead of the linear expression adopted in EN 1993-1-4 [2]. In addition, a total of six buckling curves are provided for different stainless steel grades: austenitic (EN 1.4301, 1.4401, 1.4306 and 1.4404), ferritic (EN 1.4512, 1.4003 and 1.4016), and duplex (EN 1.4462). The tangent modulus approach used in SEI/ASCE-8 and AS/NZS 4673 may also be used to predict the buckling resistance of hotfinished stainless steel tubular columns. Similarly, the same buckling curve for cold-formed hollow sections also applies to hot-finished sections in EN 1993-1-4.

\subsection{Comparison with test and FE results}

This section presents a comparison of the parametric study results obtained in Section 2 combined with the relevant test data on stainless steel compression members collected from the literature [1431 with the current column buckling curves adopted in the European and Australian/New Zealand standards. Figs 2-4 show the FE and test ultimate loads normalised by the cross-section squash loads, defined as the product of the cross-sectional area A and the cross-section yield strength $\mathrm{f}_{\mathrm{y}}$, plotted against the member slenderness $\bar{\lambda}$ for the cold-formed members. Figs 5-7 show similar results for the hot-finished members. For the cold-formed sections, the cross-section yield strength $\mathrm{f}_{\mathrm{y}}$ is taken as the weighted average $0.2 \%$ proof stress, allowing for the strength enhancements in the corner regions of the cold-formed sections. The EN 1993-1-4 [2] buckling curve for hollow sections, with the imperfection factor $\alpha=0.49$ and $\bar{\lambda}_{0}=0.4$, as well as the AS/NZS 4673 [13] buckling curve (for cold-formed sections) for each of the stainless steel grades are also depicted in Figs 2-7. To allow suitable comparison with the test and FE data, the measured geometries and material properties from the tests/FE models are adopted and all partial safety factors have been set to unity.

At high slenderness, column failure is dominated by elastic buckling, and the average stress falls in the linear part of the stress-strain curve. Hence, as expected, there is little or no difference in the buckling strength of columns of different stainless steel grades, assuming similar levels of geometric imperfections and residual stresses. This is clearly evident from Figs 2-4 and Figs 5-7, where the FE and test data are well represented by the codified curves in this slenderness range. At low slenderness, i.e. in the plateau region, columns attain or exceed the squash $\operatorname{load~}_{\mathrm{Af}}$, where the influence of different strain hardening rates, highest for austenitic and lowest for ferritic, may be observed, as shown in Figs 2-4 and Figs 5-7. The limiting slenderness beyond which member buckling rather than cross-section yielding becomes important, i.e. the length of the plateau region, 
depends on the combination of the following parameters: the $\mathrm{n}$ factor of the Ramberg-Osgood representation of the stress-strain behaviour, the yield stress $f_{y}$ and the Young's modulus E. In the intermediate slenderness range, where the average buckling stress falls between the limit of proportionality and the yield stress, taken as the $0.2 \%$ proof stress, the nonlinear stress-strain response of stainless steel leads to different buckling responses between the different stainless steel grades. The EN 1993-1-4 buckling curve is clearly not suitable for all stainless steel grades with varying nonlinear response characteristics. For the cold-formed members, a set of three new buckling curves with an imperfection factor $\alpha=0.49$ for all grades and a plateau length $\bar{\lambda}_{0}=0.3$ for the austenitic and duplex grades and $\bar{\lambda}_{0}=0.2$ for the ferritic grades have been therefore proposed herein, and are plotted in Figs 2-4. The buckling curves provided in AS/NZS 4673 [13] for coldformed members are also depicted, which for the austenitic and ferritic grades lie considerably below the test and FE data and for duplex grade is close to the curve proposed herein but with a slightly larger plateau length. Buckling curves of the same form as the EN 1993-1-4 formulation were fitted to the normalised FE data for the hot-finished tubular stainless steel columns, and are shown in Figs 5-7. The proposed curves have a plateau length $\bar{\lambda}_{0}=0.2$ for all grades and an imperfection factor $\alpha=0.49$ for the austenitic and duplex grades and $\alpha=0.34$ for the ferritic grades. Note that the positioning of the buckling curves needs to be considered in conjunction with the reliability analysis; the hot-finished duplex data, for example, appears further above the proposed buckling curve than the other grades, but this material also exhibits the lowest over-strength factor, and the resulting $\gamma_{\mathrm{M} 1}$ factors are in fact fairly constant across the grades, as shown in Section 3.3

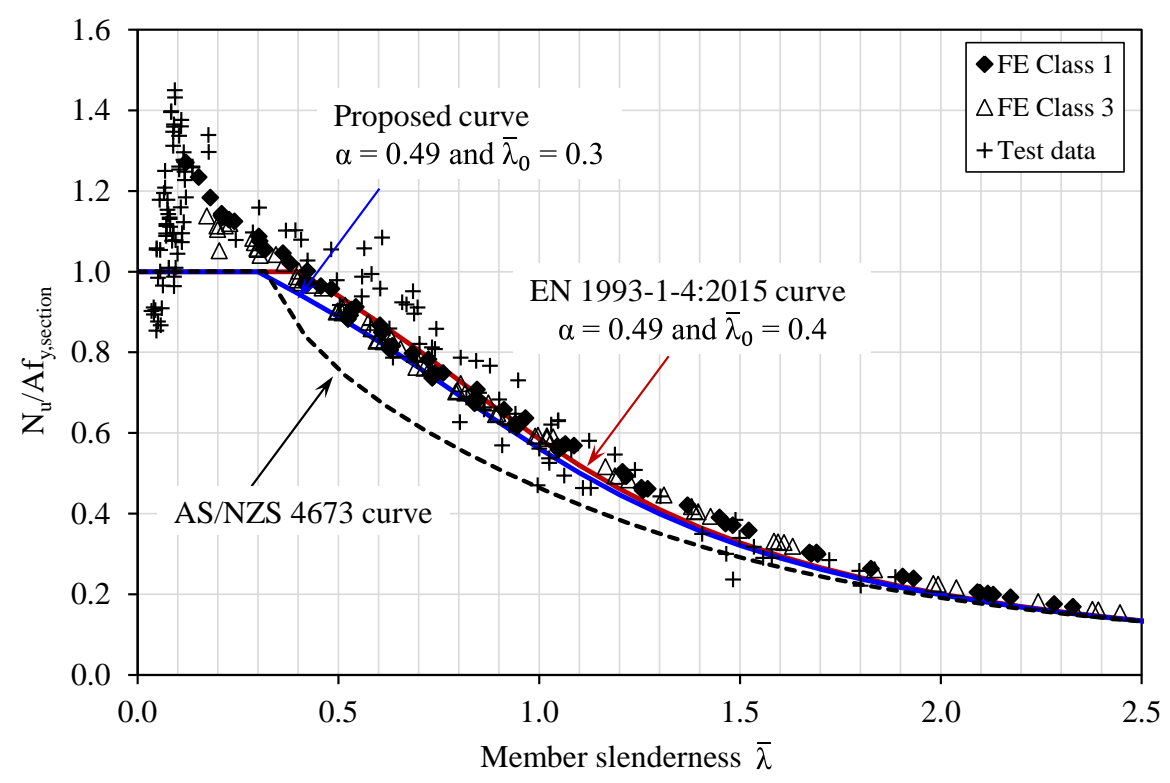

Fig. 2: Reduction factor versus non-dimensional slenderness for cold-formed austenitic SHS/RHS 


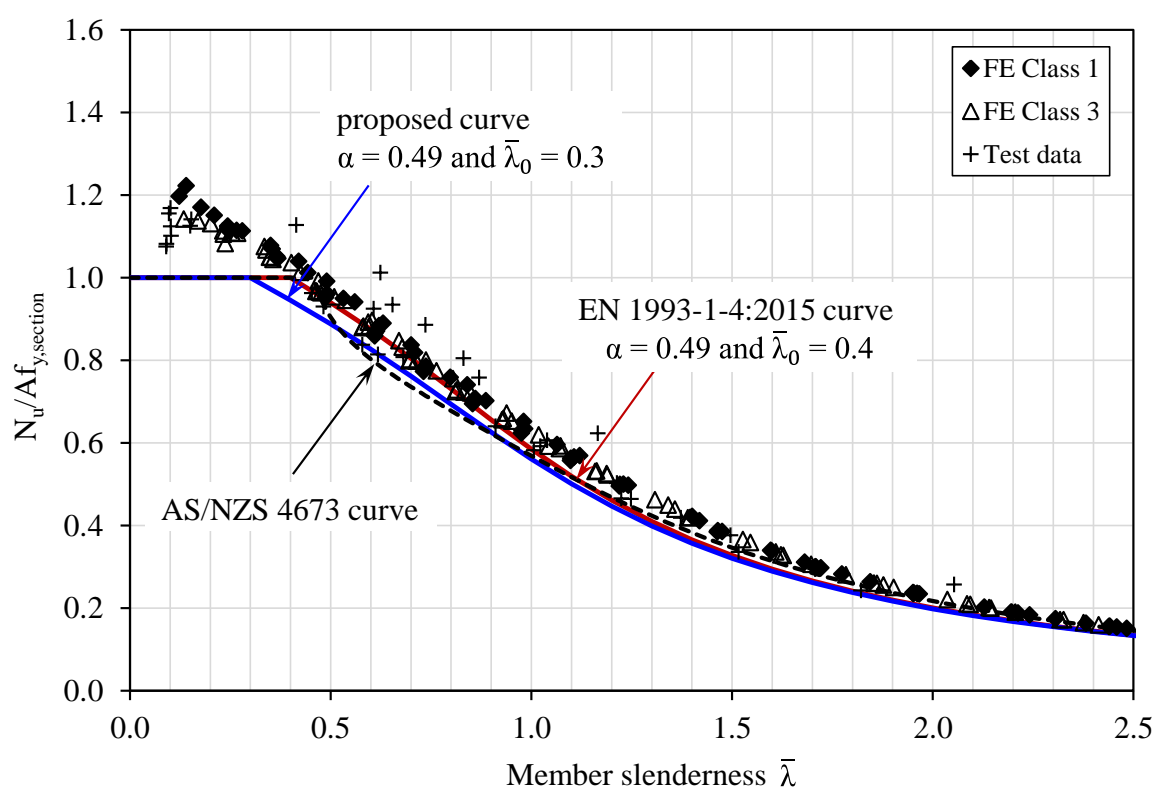

Fig. 3: Reduction factor versus non-dimensional slenderness for cold-formed duplex SHS/RHS

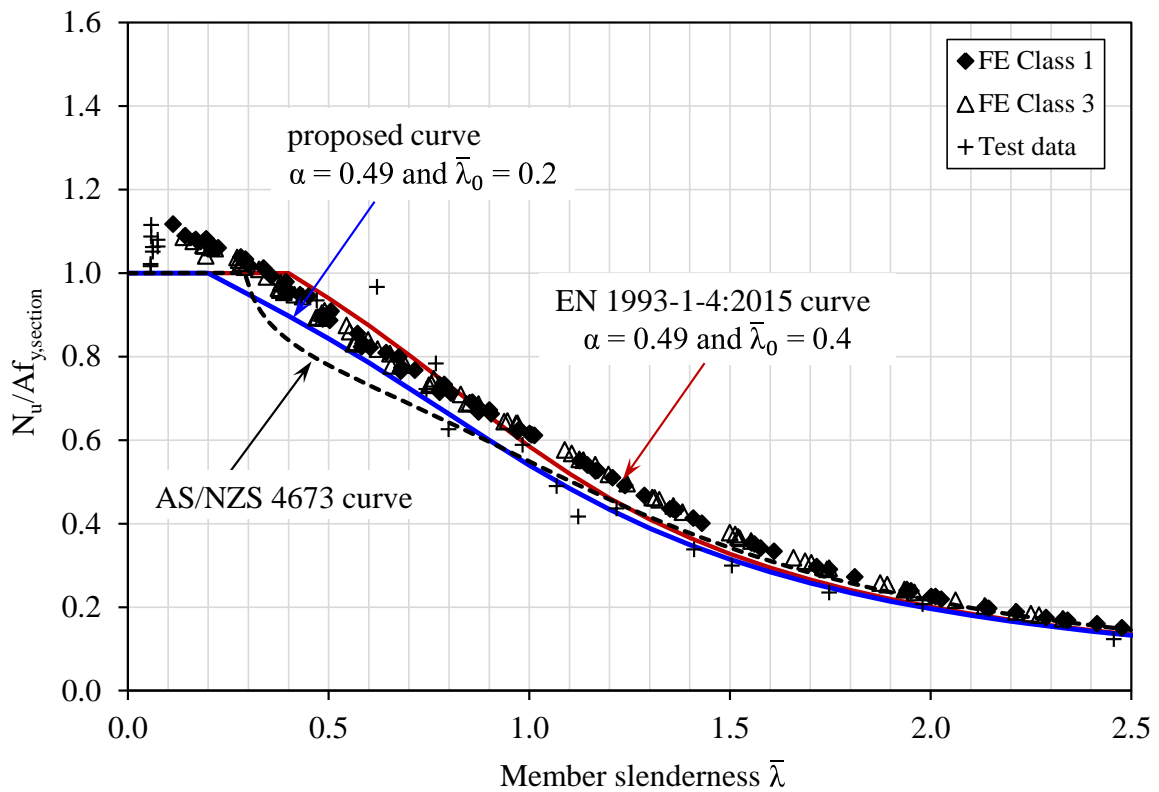

Fig. 4: Reduction factor versus non-dimensional slenderness for cold-formed ferritic SHS/RHS

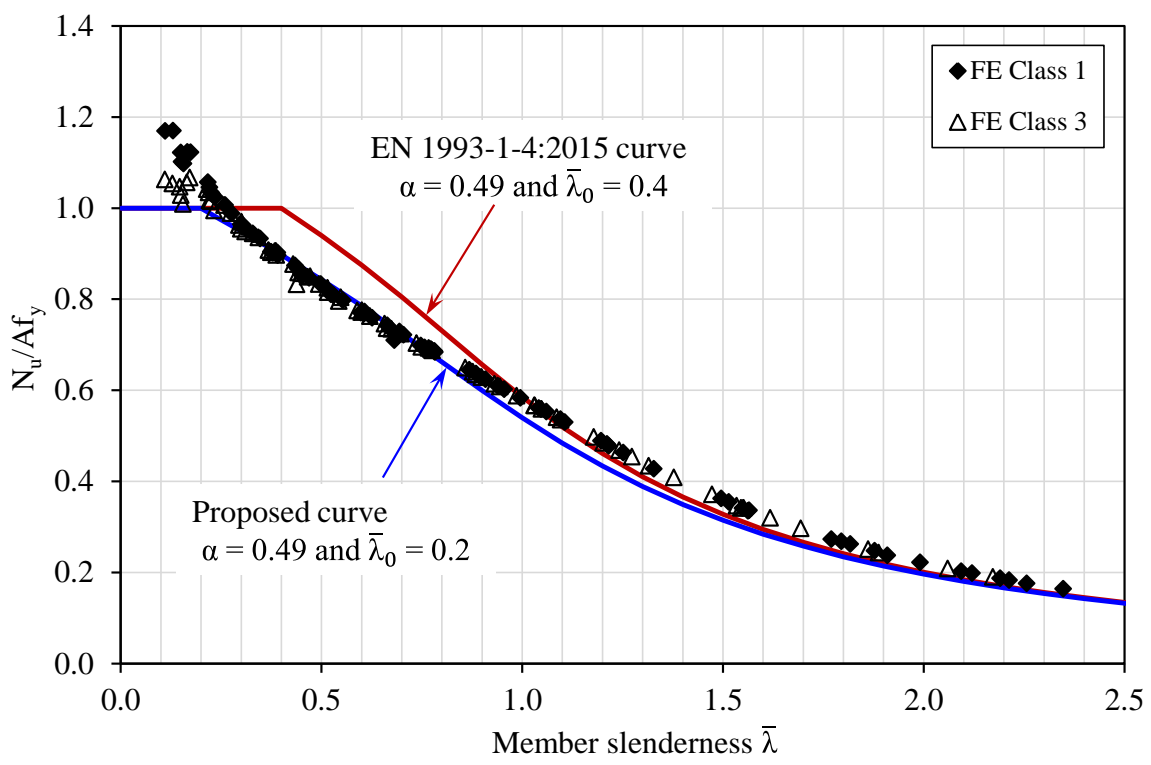

Fig. 5: Reduction factor versus non-dimensional slenderness for hot-finished austenitic SHS/RHS 


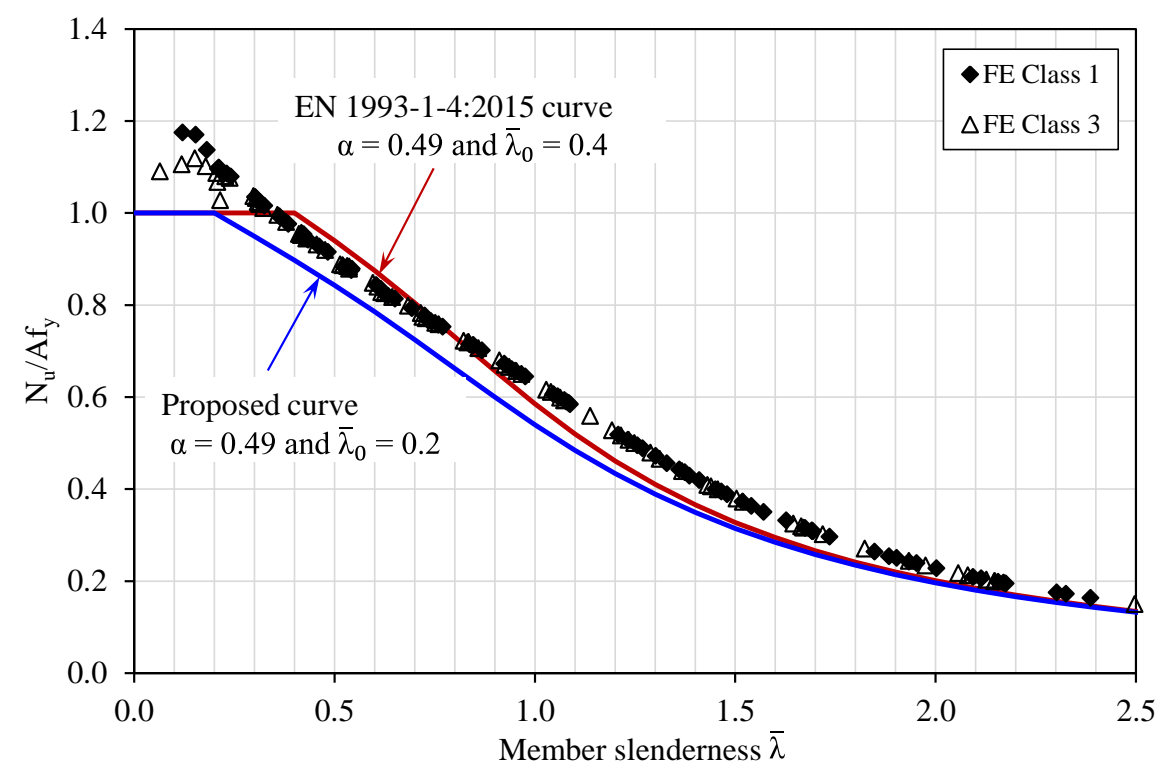

Fig. 6: Reduction factor versus non-dimensional slenderness for hot-finished duplex SHS/RHS

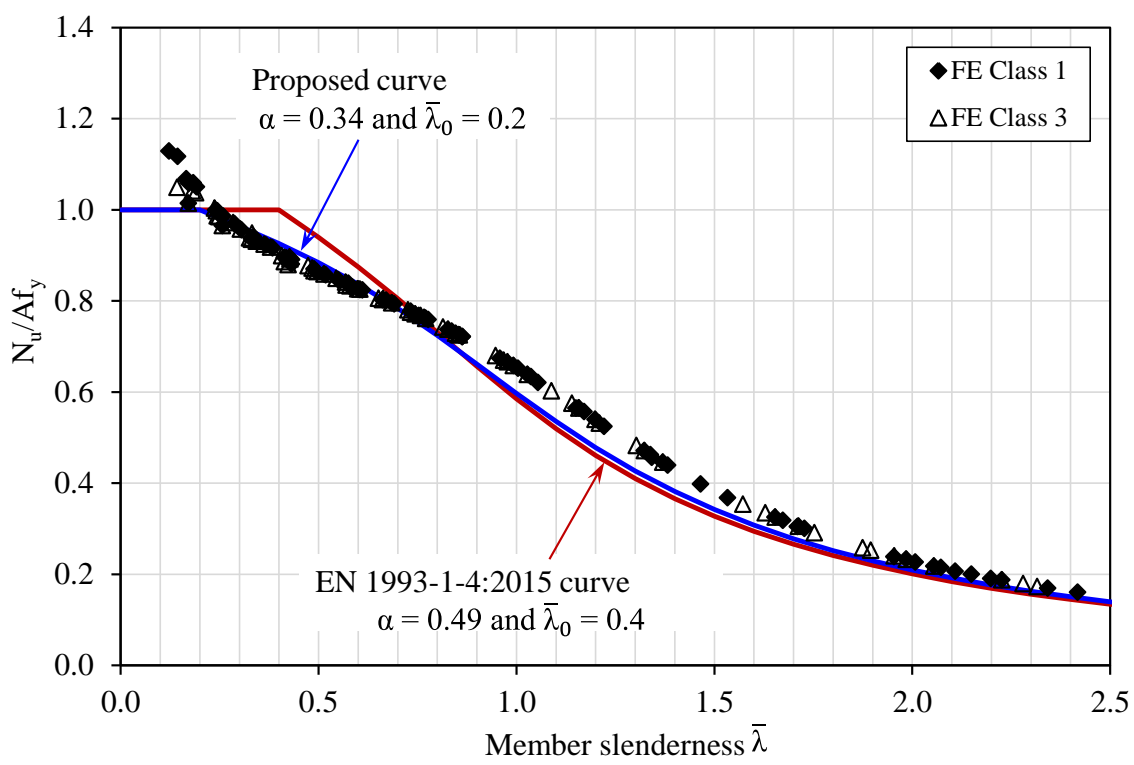

Fig. 7: Reduction factor versus non-dimensional slenderness for hot-finished ferritic SHS/RHS

\subsection{Reliability analysis}

Statistical analyses in accordance with Annex D of EN 1990 [32] were performed to assess the reliability of the proposed buckling curves for the cold-formed and hot-finished austenitic, duplex and ferritic stainless steel columns. The numerical results from the parametric studies performed in Section 2 and the collected test data are used in the statistical analyses. Representative mean to nominal yield strength ratios $\mathrm{f}_{\mathrm{y}, \text { mean }} / \mathrm{f}_{\mathrm{y} \text {,nom }}$ and coefficients of variation $(\mathrm{COV})$ of yield strength equal to 1.3 and 0.060 for austenitic, 1.1 and 0.030 for duplex and 1.2 and 0.045 for ferritic stainless steels, as recommended in [1] were employed. For the variability of the geometric properties, a $\mathrm{COV}$ value of 0.05 was used [1]. For the purpose of the reliability analyses performed herein, the design resistance equations for flexural buckling resistance set out in Clause 5.4.2 of EN 1993-1-4, as given by $E q$. (2), where $\mathrm{f}_{\mathrm{y}}$ is the material yield ( $0.2 \%$ proof) strength, $\mathrm{A}$ is the cross-sectional area (taken as the gross cross-sectional area for Class 1,2 and 3 sections and effective crosssectional area $A_{\text {eff }}$ for Class 4 sections), $\gamma_{\mathrm{M} 1}$ is the partial factor for member resistance and $\chi$ is the flexural buckling reduction factor, were expressed in a modified form as presented in $E q$. (3). This was to separate the dependency of the buckling reduction factor $\chi$ on the other basic variables (A and $\mathrm{f}_{\mathrm{y}}$ ) in the design model. In $E q$. (3), $\mathrm{k}$ is a model constant, independent of $\mathrm{A}$ and $\mathrm{f}_{\mathrm{y}}$, and $\mathrm{a}$ and $\mathrm{b}$ are the model parameters specific to each test specimen and vary with column slenderness, and their values have been evaluated following the procedures set out in [1]. 
$N_{b, R d}=\frac{\chi A f_{y}}{\gamma_{M 1}}$ for $\bar{\lambda}>\bar{\lambda}_{0}$

$N_{b, R d}=k f_{y}^{a} A^{b}$

A summary of the key results of the reliability analysis is presented in Table 2 and Table 3 for the cold-formed and hot-finished columns, respectively, where $\mathrm{k}_{\mathrm{d}, \mathrm{n}}$ is the design (ultimate limit state) fractile factor for $\mathrm{n}$ tests, where $\mathrm{n}$ is the population of test and FE data under consideration; $\mathrm{b}$ is the mean value correction factor; $\mathrm{V}_{\delta}$ is the coefficient of variation of the test and $\mathrm{FE}$ results relative to the resistance model; and $\mathrm{V}_{\mathrm{r}}$ is the combined coefficient of variation incorporating the resistance model, the numerical model and the basic variable uncertainties. Note that the $\mathrm{b}$ parameter has been taken as the average of the experimental and FE to model prediction ratios, which, unlike the least squares approach recommended in Annex D, does not bias the value of $b$ towards the test or FE results with higher failure loads. For cold-formed columns, the reliability study conducted in [1] showed that the required partial safety factors with the EN 1993-14 buckling curves are 1.16, 1.22 and 1.24 for austenitic, duplex and ferritic stainless steel grades, respectively; these are above the current recommended value of 1.1. The reliability analysis conducted herein shows that the current partial safety factor of 1.1 for member resistance of cold-formed stainless steel columns may be used with the new lower buckling curves proposed. For the hot-finished members, it is also shown that the new buckling curves proposed satisfy the Eurocode reliability level, and the current partial safety factor of 1.1 may also be used with these buckling curves.

Table 2: Summary of the reliability analysis results for cold-formed stainless steel columns

\begin{tabular}{lcccccccc}
\hline Grade & $\mathrm{n}$ & $\mathrm{b}$ & Over-strength & $\mathrm{k}_{\mathrm{d}, \mathrm{n}}$ & $\mathrm{V}_{\delta}$ & $\mathrm{V}_{\mathrm{fy}}$ & $\mathrm{V}_{\text {geometry }}$ & $\gamma_{\mathrm{M} 1}$ \\
\hline Austenitic & 285 & 1.075 & 1.3 & 3.12 & 0.071 & 0.060 & 0.05 & 1.08 \\
Duplex & 192 & 1.117 & 1.1 & 3.14 & 0.045 & 0.030 & 0.05 & 1.08 \\
Ferritic & 184 & 1.107 & 1.2 & 3.14 & 0.060 & 0.045 & 0.05 & 1.06 \\
\hline
\end{tabular}

Table 3: Summary of the reliability analysis results for hot-finished stainless steel columns

\begin{tabular}{lcccccccc}
\hline Grade & $\mathrm{n}$ & $\mathrm{b}$ & Over-strength & $\mathrm{k}_{\mathrm{d}, \mathrm{n}}$ & $\mathrm{V}_{\delta}$ & $\mathrm{V}_{\mathrm{fy}}$ & $\mathrm{V}_{\text {geometry }}$ & $\gamma_{\mathrm{M} 1}$ \\
\hline Austenitic & 160 & 1.050 & 1.3 & 3.15 & 0.056 & 0.060 & 0.05 & 1.05 \\
Duplex & 165 & 1.136 & 1.1 & 3.15 & 0.047 & 0.030 & 0.05 & 1.08 \\
Ferritic & 150 & 1.041 & 1.2 & 3.16 & 0.054 & 0.045 & 0.05 & 1.12 \\
\hline
\end{tabular}

\section{CONCLUSIONS}

A recent reliability assessment of the EN 1993-1-4 buckling resistance provisions for cold-formed compression members in [1] showed that partial safety factors greater than the currently recommended value of 1.1 are required. This indicated that lower buckling curves for cold-formed SHS/RHS members are required. Moreover, it was shown that different bucking curves for the different stainless steel grades are necessary. A comprehensive finite element (FE) modelling study was carried out in this paper to generate buckling data for cold-formed austenitic, duplex and ferritic SHS/RHS columns. These data were combined with collected test data from the literature and used to derive new buckling curves for stainless steel cold-formed SHS/RHS columns. The new buckling curves are of the same form as the EN 1993-1-4 formulation but with different plateau length values for the different stainless steel grades, 0.3 for the austenitic and duplex grades and 0.2 for the ferritic grades, to account for the effect of the different degrees of nonlinearity of the material stress-strain behaviour on the compression resistance of cold-formed stainless steel columns. The EN 1993-1-4 buckling curves for hot-finished hollow tubular sections, which are currently the same as for cold-formed members, were also assessed. Based on FE results generated herein, the existing curves were found to be unsuitable and three new buckling curves were proposed. The proposed buckling curves for hot-finished sections are again of the same form as the EN 1993-1-4 buckling curves and include a unique plateau length of 0.2 for all stainless steel grades, but different imperfection factors of 0.49 for the austenitic and duplex grades and 0.34 for 
the ferritic grades. The proposed buckling curves for both the cold-formed and the hot-finished compression members were shown to conform to the Eurocode reliability requirements, where the current partial safety factor of 1.1 was shown to be suitable.

\section{REFERENCES}

[1] Afshan S., Francis P., Baddoo, N.R., Gardner, L. "Reliability analysis of structural stainless steel design provisions", Journal of Constructional Steel Research 114, pp. 293-304, 2015

[2] EN 1993-1-4:2006+A1:2015. Eurocode 3: Design of steel structures - Part 1.4: General rules Supplementary rules for stainless steels, including amendment A1 (2015). CEN, Brussels, 2015

[3] Afshan S., Rossi, B., Gardner, L. "Strength enhancements in cold-formed structural sections - Part I: Material testing", Journal of Constructional Steel Research 83, pp. 177-188, 2013

[4] ABAQUS, Version 6.14-1. Dassault Systèmes Simulia Corp. USA, 2014

[5] Zhao O., Rossi, B., Gardner, L., Young, B. "Behaviour of structural stainless steel cross-sections under combined loading - Part II: Numerical modelling and design approach", Engineering Structures 89, pp. 247-259, 2015

[6] Arrayago I., Real E., Gardner L. "Description of stress-strain curves for stainless steel alloys", Materials and Design 87, pp. 540-552, 2015

[7] Mirambell E., Real, E. "On the calculation of deflection in structural stainless steel beams: an experimental and numerical investigation", Journal of Constructional Steel Research 54, No. 1, pp. 109-133, 2000

[8] Cruise R.B., Gardner L. "Strength enhancements induced during cold forming of stainless steel sections", Journal of Constructional Steel Research 64, No. 11, pp. 1310-1316, 2008

[9] Gardner L., Saari N., Wang F. "Comparative experimental study of hot-rolled and cold-formed rectangular hollow sections", Thin-Walled Structures, 48, No. 7, pp. 495-507, 2010

[10] EN 1993-1-1:2005. Eurocode 3: Design of steel structures - Part 1-1: General rules and rules for buildings, CEN, Brussels, 2005

[11] Ashraf M., Gardner L., Nethercot D.A. "Finite element modelling of structural stainless steel crosssections", Thin-Walled Structure 44, No. 10, pp. 1048-1062, 2006

[12] SEI/ASCE-8. Specification for the design of cold-formed stainless steel structural members, American Society of Civil Engineers, Reston, 2002

[13] AS/NZS 4673. Cold-formed stainless steel structures, Australian/New Zealand Standard, Sydney, 2001

[14] Theofanous M., Gardner L. "Testing and numerical modelling of lean duplex stainless steel hollow section columns", Engineering Structures 31, No. 12, 3047-3058

[15] Afshan S., Gardner L. "Experimental study of cold-formed ferritic stainless steel hollow sections", Journal of Structural Engineering ASCE, 139, No. 5, pp. 717-728, 2013

[16] Young B., Liu Y. "Experimental investigation of cold-formed stainless steel columns", Journal of Structural Engineering ASCE, 129, No. 2, pp. 169-176, 2003

[17] Liu Y., Young B. "Buckling of stainless steel square hollow section compression members". Journal of Constructional Steel Research, 59, No. 2, pp. 165-177, 2003

[18] Young B., Lui W.M. "Tests of cold-formed high strength stainless steel compression members", ThinWalled Structures, 44, No. 2, pp. 224-234, 2006

[19] Young B., Lui W.M. "Behaviour of cold-formed high strength stainless steel sections", Journal of Structural Engineering ASCE, 131, No. 11, pp. 1738-1745, 2005

[20] Young B., Hartono W. "Compression tests of stainless steel tubular members", Journal of Structural Engineering ASCE, 128, No. 6, pp. 754-761, 2002

[21] Burgan B.A., Baddoo N.R. Gilsenan, K. "Structural design of stainless steel members - comparison between Eurocode 3, part 1.4 and test results". Journal of Constructional Steel Research, 54, No. 1, 5173,2000

[22] Gardner L., Nethercot D.A. "Experiments on stainless steel hollow sections - Part 2: member behaviour of columns and beams", Journal of Constructional Steel Research 60, No. 9, pp. 1319-1332, 2004

[23] Ala-Outinen T. Stainless steel in fire (SSIF). Work package 3: members with class 4 cross-sections in fire, Tech. Rep. RFS-CR-04048, The Steel Construction Institute, UK, 2007

(C) Ernst \& Sohn Verlag für Architektur und technische Wissenschaften GmbH \& Co. KG, Berlin · CE/papers (2017) 
[24] SCI, Tests on stainless steel materials, Tech. Rep. SCI-RT-251. The Steel Construction Institute, UK, 1991

[25] Baddoo N.R., Gardner L. Final report. ECSC project - development of the use of stainless steel in construction, Tech. Rep. RT810, Contract No. 7210 SA/842. The Steel Construction Institute, UK, 2000

[26] Gardner L., Nethercot D.A. "Experiments on stainless steel hollow sections - Part 1: material and crosssectional behaviour", Journal of Constructional Steel Research, 60, No. 9, pp. 1291-1318, 2004

[27] Gardner L., Talja, A., Baddoo, N.R. "Structural design of high-strength austenitic stainless steel”, ThinWalled Structures, 44, No. 5, pp. 517-528, 2006

[28] Young B., Lui W.M. "Behaviour of cold-formed high strength stainless steel sections", Journal of Structural Engineering ASCE, 131, No. 11, pp. 1738-1745, 2005

[29] Rasmussen K.J.R., Hancock D.A. "Design of cold-formed stainless steel tubular members. I: columns". Journal of Structural Engineering ASCE, 119, No. 8, pp. 2349-2367, 1993

[30] Kuwamura H. "Local buckling of thin-walled stainless steel members". Steel Structures, 3, No. 3, pp. 191-201, 2003

[31] Huang Y., Young B. "Material properties of cold-formed lean duplex stainless steel sections", ThinWalled Structures, 54, pp. 72-81, 2012

[32] EN 1990. Eurocode: Basis of structural design, CEN, Brussels, 2002 